\title{
LA CASA DE CORREOS DE SAN MIGUEL ALLENDE: DE MONUMENTO NACIONAL A CONFORTABLE RESTAURANTE PARTICULAR
}

Compilación de Martha Fernández

Todo comenzó el 16 de febrero de 1986. Un hecho insólito tuvo lugar en la ciudad de San Miguel Allende: el pueblo organizó un plantón frente al Ayuntamiento para pedir a las autoridades que impidieran la alteración de únos de sus monumentos, la Casa de Correos ubicada en la calle del mismo nombre y marcada con los números 10,12 y 14 . A los sanmigueleños nos unimos básicamente dos investigadores de esta Universidad: el Mtro. Jorge Alberto Manrique y quien esto escribe, amén de algunas agrupaciones que tienen como principal objetivo defender nuestro patrimonio histórico y artístico, tal como la Sociedad Defensora del Tesoro Artístico de México.

La polémica comenzó: los propietarios de la casa de San Miguel Allende defendiendo sus intereses, y los demás, defendiendo nuestro patrimonio. Por el interés que puede representar para los universitarios en particular y para los mexicanos en general la salvaguarda de nuestros valores históricos y artísticos, y por la necesidad que existe de que todos tomemos conciencia de los inmensos problemas a los que nos enfrentamos en este terreno, el Instituto de Investigaciones Estéticas ha considerado pertinente reproducir aquí la polémica que se desarrolló en la prensa por la defensa de la Casa de Correos de San Miguel Allende y sus incalificables resultados.

Una vez que se recibió la noticia del plantón organizado por el pueblo de San Miguel Allende, Jorge Alberto Manrique publicó en el diario La Jornada, el día 11 de marzo de 1986, un artículo que tituló "Destrucción de San Miguel Allende" y cuyo texto es el siguiente:

Si uno mira la situación de nuestro patrimonio cultural no puede menos que sentirse crucificado por situaciones contradictoritâs. Por una parte es innegable que en algunos sentidos se han hecho avances considerables: las instituciones oficiales hacen esfuerzos consistentes y toman medidas adecuadas en pro de su salvaguarda; organismos no oficiales coadyuvan constantemente al mismo fin y, quizá más importante, cada vez se siente más una conciencia del valor de nuestro patrimonio. Esa conciencia ha hecho que autoridades estatales y municipales realicen obras de restauración y de dignificación de los monumentos y zonas 
monumentales. Ella misma ha hecho, cada vez más, que las comunidades intervengan en defensa de un patrimonio que es suyo y que no están dispuestas a dejar desaparecer, mermando asi la herencia que dejaremos al país.

Pero por desgracia los actos vandálicos contra el patrimonio no cesan, son pan de todos los días y disminuyen constante y ferozmente la riqueza central de México. En muchos casos son resultado de la falta de conciencia, de la ignorancia que lleva a la aniquilación de nuestros conjuntos urbanos. En otros se trata, en la forma más descarada, de hechos en que el interés económico particular se impone brutalmente sobre el interés de la comunidad, desoyendo toda opinión bien intencionada y violentando toda ley. Eso es lo que actualmente está a punto de suceder en San Miguel Allende.

San Miguel Allende es sin duda una de las ciudades más hermosas de México. Su conjunto urbano, de hermosas casonas y bellas iglesias, es un testimonio magnífico de la vida mexicana del siglo XVIII, de una época de bonanza por la relación entre esa zona agrícola y los cercanos reales de minas. En cierta medida aislado de los cambios más fuertes de las estructuras mexicanas en el siglo XIX, pudo conservar su hetmoso carácter testimonial. Ya entrado este siglo sus habitantes, conscientes del tesoro del que eran custodios, se han preocupado por mantenerlo; a ellos se sumaron pronto los fuereños, mexicanos o no, que llegaron a San Miguel a vivir, atraídos por el sitio histórico. Es un caso en el que la comunidad sanmigueleña ha contribuido a la salvaguarda de un patrímonio que no es sólo de ellos, sino de México y del mundo.

Ahora una de sus mejores casas, la Casa del Correo, está en vías de ser destruida por su propietario, para adaptarla bárbaramente a fines de usufructo turístico. Ni las protestas de los habitantes de San Miguel ni la intervención del Instituto Nacional de Antropología e Historia han podido detener en su nefasto designio a quien dice tener poder económico y político suficiente para burlar toda ley y toda autoridad. El Instituto de Antropología ha sellado la obra, por contravenir la ley y los reglamentos, y los vándalos los han violado y han continuado la demolición.

Lo que está en juego es el patrimonio de una ciudad de la importancia monumental de San Miguel Allende, y simultáneamente la existencia de un estado de derecho. ¿Es posible realmente que en México un individuo que se dice poderoso pueda violentar las leyes y burlar la autoridad para obtener una ganancia particular en detrimento del patrimonio cultural de la nación? ¿Nadie podrá impedirlo? Las más altas autoridades estatales y federales tienen la palabra.

El principal argumento que manejó Manrique con ese artículo fue el carácter testimonial de la villa completa de San Miguel Allende de una parte de la historia de México y de una región concreta.

Ahora bien, del articulo también cabe destacar el hecho de que el Instituto Nacional de Antropología e Historia había clausurado las obras de 
adaptación de esa casa que fueron violados por los propietarios para continuar firmemente tras el objetivo que perseguían. Hasta ese momento sólo existía un sólo destructor: los propietarios.

Dos días después de que este artículo apareció en la prensa, o sea el 13 de marzo, vio la luz en el periódico Excélsior un artículo mío bajo el título de "San Miguel Allende: impidamos la alteración", en el cual también hago destacar la violación de las disposiciones de las autoridades competentes, por parte de los propietarios, e intento fundamentar la defensa de la casa con datos históricos y artísticos más concretos. He aquí lo que escribí en aquella ocasión:

Al acercarse la Semana Santa, lo primero que viene a la mente es el deseo de salir de la ciudad. El primer recuerdo que yo tengo de una celebración de Semana Santa con procesiones religiosas dentro de un espíritu europeizante, es la de San Miguel de Allende. Una población de fuerte personalidad artística que posee la virtud de combinar por sus calles monumentos de sobria riqueza barroca con otras que lucen los más diversos estilos del siglo XIX, hasta llegar a la parroquia neogótica que soberbia se levanta al centro de su plaza mayor.

Esta villa es una de esas rarezas que luce prácticamente sin alteración y por expresa voluntad de sus habitantes, las características originales de sus edificios y que ha convertido a San Miguel de Allende en uno de los sitios más atractivos y acogedores de México.

Su arquitectura civil barroca posee un carácter muy personal, tanto que al referirse a ella Diego Angulo explica en su obra Historia del Arte Hispanoamericano ( 3 t., Barcelona, Salvat Editores, 1945-50) que 'la casa sanmigueleña, aun con sus cornisas rectilíneas, tan dignas de ser tenidas en cuenta en tierra de cornisas rizadas, son más barrocas y de estilo lo suficientemente uniforme para descubrimos la presencia de un arquitecto de cierta personalidad que se impone a sus contemporáneos. En general, esas fachadas se distinguen por la importancia concedida al encuadramiento de sus balcones. Cada arquitecto y cada escuela cultiva con particular cariño una parte de la fachada, y en San Miguel el Grande el abolengo de la familia parece querer reflejarse en el lujo con que se decora el gran saledizo en que el balcón se apoya y el tejarez con que se cubre'.

De este estilo es una casa que da nombre a una calle de San Miguel: la antigua casa de Correos, marcada en la calle con los números 10 y 12. De ella nos habla el doctor Gustavo Curiel, investigador del Instituto de Investigaciones Estéticas de la UNAM. La casa es de un solo nivel, con cornisa recta y los vanos de las ventanas están enmarcados por jambas y cornisas individuales. En este sentido, la casa participa de las características que son comunes a las sanmigueleñas. Pero también tiene elementos distintivos, como los arcos rebajados y multimoldurados de las puertas, que en opinión de Curiel, es una de las solu- 
ciones más audaces de la arquitectura colonial del Bajío, en donde la mayor parte de las casas habitación son arquitrabadas.

En el interior, afirma el entrevistado, conserva uno de los patios más bellos de San Miguel: de una sola planta, porticado y con una fuente monumental al centro.

Pero además, esta casa tiene una historia que Curiel nos cuenta así: A principios del siglo pasado fue propiedad de José Manuel de Sauto; hacia los albores de la Independencia se convirtió en oficina de Correos, más tarde pasó a ser propiedad de la familia Redondo, quien después de habitarla un tiempo la alquiló al gobierno del Estado para establecer en ella la Academia de San Miguel. A principios de los años sesenta de este siglo, se instaló ahí una discoteca-restaurante, que alteró en parte el espacio y convirtió el patio en pista de baile previamente cubierto con techo de lámina. La lujosa discoteca fue desvirtuándose hasta convertirse en una cantina. Ahora ha vuelto a tener su uso original: el de casa habitación, pero el precio que ha de pagar por ello parece ser muy alto.

Los actuales propietarios están construyendo a la casa un segundo nivel. La obra fue detenida por el gobierno de Guanajuto, pero según la información que obtuvo Curiel, los sellos de clausura se rompieron y la obra se continuó sin la menor intervención del INAH, ni de ningún otrō organismo encargado de la conservación de nuestro patrimonio nacional. Pero, al parecer, los habitantes de San Miguel de Allende no están dispuestos a permitir que el aspecto de la villa cambie, es su voluntad protegerla $y$, en una elocuente toma de conciencia de los valo. res artísticos de sus monumentos, el domingo 16 de febrero realizaron un plantón frente a la presidencia municipal para protestar por las alteraciones de la antigua casa de Correos, pues saben bien que este puede ser sólo el principio de lo que puede ocurrirle a esa tradicional villa si permiten por una sola vez cambios en las características originales de sus edificios.

Es entonces importante y urgente que se impida la alteración de esa casa no sólo por sus cualidades artísticas, su tradición histórica, por encontrarse a sólo unos metros de la plaza mayor, por integrarse perfectamente a su contorno urbano y porque sus características originales fueron proyectadas para poseer un solo nivel, sino porque esa es la voluntad del pueblo.

Un evidente error en la información que registré en ese artículo es el de haber considerado que la casa en cuestión volvería a tener su uso original de casa habitación, pues desde entonces ya se sabía que su destino sería el de restaurante.

Pero lo más importante es que, pese a la pública denuncia hecha en su oportunidad en la prensa, los trabajos en la casa continuaron y su alteración parecía cada vez más grave, de esta suerte, Jorge Alberto Manrique volvió a insistir. El 25 de marzo publicó en La Jornada un artículo más que tituló "Vándalos en San Miguel Allende". 
En esa ocasión sólo se concretó a resaltar dos hechos: el carácter de "bien no renovable" del patrimonio monumental, y la necesidad de hacer cumplir una ley nacional para proteger nuestro patrimonio que ya existía: la Ley Federal de Monumentos y Zonas Arqueológicas, Históricos y Artísticos de 1972.

Así, el artículo dice:

Una de las condiciones del patrimonio monumental es su carácter de bien no renovable. Una vez perdido un monumento o un conjunto monumental, éste no puede ser de ninguna manera recuperado. Esa circunstancia hace que el patrimonio de la humanidad, en términos de los monumentos del pasado, siempre se disminuya: se le puede restar, y de hecho y por desgracia continuamente se le resta; nunca se le puede agregar.

Entre los factores que más violentamente han contribuido a la disminución del patrimonio de la humanidad está el de la especulación con los bienes urbanos. Los propietarios, en busca de su propio beneficio, a menudo derriban, alteran o degradan fincas urbanas para conseguirlo, sin importarles el daño irreversible que causan a un conjunto urbano y por ende a la comunidad que lo habita y al patrimonio de la nación y del mundo.

Esa pérdida acelerada de un patrimonio que es de todos, y que una vez perdido es irrecuperable, ha llevado a las naciones y a los organismos internacionales a tomar medidas para contrarrestarla. Los países han proclamado leyes particulares y generales, los organismos internacionales han producido normas y criterios que permiten la mejor salvaguarda del patrimonio monumental y la reutilización de los bienes muebles para las formas actuales de la vida urbana; organizaciones como la UNESCO han patrocinado instrumentos, la Convención del Patrimonio Mundial, que entendiendo la necesidad de preservar una herencia que constituye la conciencia de toda la humanidad, propicia medios de colaboración internacional en su favor.

La conservación del patrimonio implica recursos técnicos y económicos de los cuales un país pobre como el nuestro, y simultáneamente inmensamente rico en testimonios de su pasado, no siempre puede disponer. Pero a menudo basta la simple aplicación de la ley, que no implica recursos mayores, sino la voluntad de cumplirla, para evitar la acción vandálica.

Ese es el caso en San Miguel Allende, donde un propietario abusivo ha alterado y desfigurado sustancialmente una de las casas que dan orgullo a la población, cuyo carácter histórico ha sido celosamente conservado por sus habitantes y es asombro de los extraños. La destrucción de la Casa del Correo de San Miguel no sólo implica la pérdida de esa finca, sino que daña a la población toda.

La Ley Federal de Montumentos y Zonas Arqueológicas, Históricos y Artísticos, de 1972, señala que si el propietario de un bien monumental 
lo alterara, está obligado a restituirlo a su estado original a su propio costo, y que si así no lo hiciere, el Instituto correspondiente hará la restitución y la autoridad fiscal le presentará al propietario la cuenta del gasto respectivo.

Es indudable que un bien restituido no es ya el bien original, y que siempre debe preferirse evitar la destrucción. Pero cuando el legislador decidió esa disposición tuvo seguramente en cuenta que es preferible un mal menor, como es la restitución, al mal mayor que significa la desfiguración del monumento y la alteración del conjunto en que se halla inserto; y tuvo también en cuenta el sentido de ejemplaridad que la restitución implica para quien tan irresponsablemente actuó en contra de un bien que es, en su carácter monumental, herencia de la comunidad. Se quiso evitar caer en la situación, antes muy común, de que un propietario se apresurara a destruir, porque una vez el daño consumado no había nada que hacer.

Afortunadamente la situación legal actual es diferente. El destructor de la Casa del Correo de San Miguel debe sujetarse a ella, culquiera que sea el poder económico y político que dicen que tiene. La autoridad, tanto la de la Secretaría de Educación Pública y del Instituto de Antropología e Historia, como la municipal y la estatal de Guanajuato, que según la propia ley de 1972 está obligada a coadyuvar a su cumplimiento, debe imponer al propietario la restitución del inmueble a su estado original. Al hacerlo no sólo cumpliría con su obligación, sino que no defraudaría a la comunidad de San Miguel Allende, que tan valientemente ha defendido su ciudad, y mostratía la responsabilidad a que la obliga el patrimonio de la nación.

Sería tristemente irónico que ahora que México accede con pleno derecho a la Convención del Patrimonio Monumental de la UNESCO, se mostrara negligente en el cuidado de su propio patrimonio, teniendo, como tiene, los instrumentos legales suficientes.

Después de tantos intentos realizados por los sanmigueleños y por nosotros, parecía que al fin se iba consiguiendo algo. A principios del mes de abril, los propietarios de la Casa de Correos de San Miguel Allende tuvieron que enviar los proyectos de alteración que proponían al INAH para ser "aprobados". La Dirección General de Monumentos Históricos de esa Institución organizó una reunión de trabajo para analizar tales proyectos y tomar un acuerdo "definitivo".

En el análisis se descubrió que el patio de la casa se había desalojado de las construcciones provisionales que le habían agregado y su aspecto había mejorado; que habían reconstruido tres galerías del segundo piso que la Ley no les podía obligar a tirar porque ya existían cuando se compró la casa por última vez, y que lo que verdaderamente alteraba por completo la casa eran algunos espacios interiores que ya no podían volver 
a adquirir su aspecto original, y la galería que se había levantado en el segundo piso de la fachada.

El acuerdo del INAH fue drástico y tajante en aquella ocasión; se obligaría a los propietarios a derribar la galería del segundo piso que daba a la fachada y se les cobraría la multa que señala la ley por intervenir sin ninguna autorización en un monumento nacional.

Todo parecía indicar que se había podido salvar la casa, que habíamos triunfado, de manera que el 17 de abril pubiiqué en Excélsior un artículo con el alentador título de "La unión hace la fuerza: casa colonial salvada", cuyo texto es el siguiente:

Una de las pruebas de la veracidad de aquel dicho popular que afirma que "la unión hace la fuerza", la encontramos en la casa que hoy tiene los números 10, 12 y 14 de la calle de Correos en San Miguel Allende, Guanajuato.

Durante los meses de febrero y marzo se levantó una ola de indignación debido a que esa casa que tenía una larga historia, que era una tradición en San Miguel y que era representativa del arte barroco del Bajío, estaba siendo alterada por su actual propietario. Las protestas surgieron no sólo entre los académicos y enterados, sino incluso entre los habitantes de esa histórica ciudad, quienes organizaron un plantón frente a la Presidencia Municipal para manifestar su inconformidad ante las modificaciones que arbitrariamente se estaban haciendo a la casa que antaño fueran las oficinas del Correo.

En efecto, a la casa se le levantó un segundo piso que, si bien, unificaba la altura de los edificios de esa calle, alteraba sustancialmente a la casa misma. Por supuesto, en ese segundo piso se procuró respetar algunas características del primero, pero interpretadas al arbitrio del constructor, por ejemplo, en los vanos invirtieron la guardamalleta que lucen las ventanas del primer piso que están donde deben de estar, o sea debajo del repisón de los balcones, y las colocaron, en el segundo, a manera de remate formando un conopio.

El doctor Gustavo Curiel, investigador del Instituto de Investigaciones Estéticas de la UNAM, entrevistado nuevamente acerca de este asunto, nos informó que a él le impidieron el acceso al interior de la casa. Sin embargo, el maestro Jorge Alberto Manrique, también investigador de ese Instituto, tuvo acceso a la documentación que los propietarios de la casa enviaron al INAH para su aprobación, y es él, quien accediendo a ser entrevistado, nos informó que el interior se vio menos afectado por la intervención de que fue objeto en tanto que liberaron el patio, pero que indudablemente también se alteraron irreversiblemente muchos espacios.

Ahora bien, aunque las modificaciones que sufrió la casa fueron menos monstruosas de lo que pensamos en un principio, puesto que hacia la fachada se intentó medio imitar el estilo del primer piso, y en el interior se liberó el patio, de todos modos, son cambios que se hicie- 
ron arbitrariamente a un monumento nacional y que necesariamente lo altera en sus características originales. Es por ello, que el maestro Manrique nos informó que en el INAH se había acordado obligar a los propietarios a derribar la galería del segundo piso que da a la fachada y permitir que las tres galerías posteriores permanezcan. Además de que los propietarios tendrán que pagar la multa que señala la ley por intervenir sin autorización de nadie en un monumento nacional.

En lo personal, hubiera preferido que derribaran todo el segundo piso, pero me explicó Manrique que parte de esas galerías ya existian. Fueron edificadas también indebidamente quién sabe cuándo, pero hace cierto tiempo, y nadie puede obligar a los actuales propietarios a tirar lo que ya estaba. La solución intermedia fue entonces hacer que se tire lo que más afecta a la casa y que sí fue obra de los actuales propietarios: la galería que da a la fachada de la casa.

De esta historia podemos sacar, como en las fábulas, dos moralejas. Primero: se permitió que en un tiempo histórico no determinado se elevara un piso a esta casa, como se permitió que se hiciera con muchas más, porque de ello abundan los ejemplos: ahora debemos pensar en la manera efectiva de evitar en lo sucesivo estas alteraciones. Segundo: hemos podido comprobar que si nos unimos podemos evitar el vandalismo en nuestros monumentos. En este momento parece que hemos salvado una casa colonial. Más tarde, podriamos conseguir la salvaguarda de todo nuestro patrimonio nacional.

Nuestro arranque de optimismo, sin embargo, duró muy poco tiempo, ni siquiera alcanzó el mes, porque el 8 de mayo Guadalupe Appendini publicó, también en el Excélsior, una entrevista que realizó con el Ing. Vicente García Torres, apoderado de los dueños de la casa de San Miguel, en la que no sólo desmiente el acuerdo del INAH, sino que incluso da a conocer el número de licencia que le otorgó esta Institución para poder continuar con los trabajos de alteración de esa casa. He aquí el contenido de la entrevista:

'Propiciar el turismo hacia nuestro país, atender con cortesía a los visitantes y proporcionarles lugares bellos y confortables a la categoría de México, es un deber de todos', dijo el ingeniero Vicente García Torres.

Nuestro entrevistado es originario de San Miguel Allende y ama a su patria chica, cuna de nuestra Independencia, que es, por su belleza, uno de los lugares más visitados por el turismo extranjero. Nos habló sobre una denuncia hecha por esta reportera en el sentido de que se estaba afectando una construcción del siglo XVIII, en el corazón de aquella ciudad.

Sin el propósito de provocar polémicas sobre este asunto, publicamos las opiniones del ingeniero García Torres, apoderado de los dueños del mencionado inmueble, de la calle de Correo No. 10 en San Miguel Allende. 
Manifestó que 'esta casa iba a ser de dos plantas, como todas las de la manzana en que se encuentra, pero sólo hicieron una, de grandes habitaciones y tres corredores, que rodea al enorme patio andaluz. La obra quedó inconclusa y hasta abandonada durante muchos años. Llegó a ser asilo de ancianos. Luego se le empezó a adaptar para casa particular y a continuación para restaurante con el nombre de 'El Patio', así funcionó unos 35 años. Pero se abusó de su limitada capacidad al agregarle cuartuchos y 'pegotes' por todas partes, hasta hacerlo inoperante. Especialmente la azotea se cubrió en 70 por ciento de pésima construcción (allí se hicieron los baños) y le dieron al edificio un aspecto deplorable. La relevancia del inmueble bajó entonces a su mínima categoría.

'En 1985, la Promotora Valle de Alcocer compró el inmueble, e intervino el licenciado José Benigno Torres Orozco para restaurarlo, volverlo al estado original y hasta terminar la parte inconclusa, respetando su fisonomía. Por supuesto, de inmediato se pidió permiso a las autoridades respectivas, especialmente al Instituto Nacional de Antropología e Historia, quien tuvo a bien expedir la licencia número 40122-180, actualmente en plena vigencia.

'Se ha utilizado el trabajo profesional de arquitectos, ingenieros y hasta gastrónomos en el nuevo restaurante. Las obras llegan casi a su final, y pronto tendrá San Miguel Allende un establecimiento digno de su categoría turística'.

Agregó el licenciado García Torres que la planta baja quedó tal como se encontraba en el siglo XVIII. En la azotea se cambiaron los cuartuchos y pegotes por habitaciones formales. Ya tiene el inmueble su fachada completa, con dos niveles iguales de la misma altura y estilo de los edificios colindantes. 'No se alteró el perfil arquitectónico de la calle de Correo ni la volumetría de la manzana en que se encuentra la casa. Mucho menos se dañó San Miguel. Sólo se hizo una restauración sin perjudicar a nadie. Nuestro deseo es ayudar, servir al municipio, a la ciudad que nos vio nacer'.

Sobre la 'supuesta demolición del edificio de Correos de San Miguel de Allende, me permito confirmarle ahora mi explicación verbal de que nunca ha existido tal peligro. Probablemente confundieron este edificio con el colindante (Núm. 10 de la misma calle), que se encuentra en restauración desde el año pasado y ahora servirá de referencia en el comentario siguiente: Hacia 1938 se colocó una placa conmemorativa errónea, junto al marco del zagúan del inmueble citado, con la inscripción 'Primitiva Casa de Correos'. Lo discutible radica en que San Miguel se fundó en 1542, e inmediatamente tuvo Correo por encontrarse en la ruta de las antiguas 'conductas' coloniales en el camino hacia las provincias internas y por haber adquirido rápidamente importancia comercial. Si el inmueble en restauración se construyó hasta el siglo XVIII, o sea mucho después de la fundación de la antigua Villa, en su lugar no pudo ser establecida la 'Primitiva Casa de Correos'. El verdadero Correo ya andaba seguramente dando tumbos por otras calles, 
como lo ha hecho en los últimos tiempos, ocupando locales de las calles de Reloj, Mesones, Hidalgo, etc. etc.

'Lo mismo ha ocurrido con Teléfonos y Telégrafos, al ser instalados en diversas casas, sin que nadie por eso las haya declarado monumentos históricos.

'También el inmueble de Correo 10 es citado en un catálogo oficial, como sede del Mayorazgo de Sautto. Los mayorazgos eran, simplemente, arreglos civiles o familiares que autorizaban a los primogénitos a administrar el patrimonio familiar y no creo que por eso, los hogares respectivos alcanzaran la categoría de monumentos históricos.

'Funcionaron en forma tan arbitraria e irregular' que fueron abolidos por el gobierno de México a mediados del siglo pasado.

'No figura el llamado mayorazgo de Sautto en 'Los Mayorazgos de la Nueva España' (obra editada por la UNAM). En el 'Nobiliario Español' aparece el apellido como originario de Oquendo, pero sin la doble t.

'Por la cronología, posiblemente se trate del mismo Baltasar de Sautto que radicó en San Miguel el Grande: trabajó mucho, se volvió potentado. El o su hijo mayor edificaron quizás, la casa de la calle Correo 10, a la que nos referimos.'

Por supuesto, el texto de esta entrevista merece varios comentarios. En primer lugar, el Ing. García Torres afirma que esta casa se iba a construir de dos pisos como todas las de la manzana, peto quedó inconclusa. Ciertamente, todas las demás casas de la manzana son de dos pisos, pero fueron construidas en el siglo XIX y a principios de éste. La Casa de Correos de San Miguel Allende fue construida en el siglo XVIII, o sea antes que las que conforman el resto de la manzana. Lo que equivale a decir, haciendo uso del mismo sistema de falacias empleado por el Ing. García Torres, que Ias casas que se construyeron mal fueron las otras.

Pero si nos avocamos a la verdad histórica, nos encontramos con que no existe ningún documento, ni plano alguno que nos indique que efectivamente esta casa debía haber tenido dos niveles. De hecho, ni siquiera conocemos el nombre de su arquitecto. En cambio, por las características que poseía la casa misma, daba la impresión de que la casa había sido planeada para un solo piso: incluso de la cornisa salían los botaguas hacia la calle.

En segundo lugar, el Ing. García Torres asegura que para modificar la casa se utilizó el trabajo profesional de arquitectos, ingenieros ". . .y hasta gastrónomos...". Sólo que al ingeniero se le olvidó incluir restauradores, únicos especialistas que seguramente con intereses menos comerciales y más artísticos, hubieran determinado lo que se podía y no se podía realizar en esa casa.

La entrevista llega a su climax cuando el Ing. García Torres intenta fundamentar la destrucción de la casa desde el punto de vista histórico. Afir- 
ma, por ejemplo, que el INAH se equivocô al poner una placa en esa casa indicando que "ahí se ubicó la Primitiva Casa de Correos", porque esta casa se construyó mucho después de haberse fundado la Villa de San Miguel; pero que aunque esto fuera cierto, no por ello se debe declarar a la casa monumento nacional, porque, por ejemplo, Teléfonos y Telégrafos también han tenido sus respectivas sedes en casas particulares sin que hayan sido afectadas con una declaratoria de monumento. Y finalmente, invistiendo sus mejores galas de investigador, concluye que Sauto y Sautto no es el mismo apellido:

No parece necesario responder a tanta falsedad; parece claro que los argumentos empleados por el Ing. García Torres no pueden ser tomados en serio. En cambio, debemos comentar un poco el asunto de la licencia concedida por el INAH para alterar la casa.

La licencia a la que hace referencia el Ing. García Torres no fue concedida al principio de la intervención en la casa. Como hemos visto, cuando la obra se iniciaba, fue clausurada. De manera que el INAH debió expedir la licencia hacia la segunda quincena del mes de abril. Ahora bien, ¿por qué se expidió?

En comunicación verbal, la Mtra. Sonia Lombardo, directora de Monumentos Históricos del INAH, nos dijo a algunos asistentes a cierta reunión del Comité Mexicano de Historia del Arte que "no se había podido hacer nada, porque la casa no estaba declarada monumento nacional". Desde luego, la sorpresa fue inmensa, pero este argumento también se derrumbó pronto. Yo misma encontré la declaratoria en el Diario Oficial de la Federación, publicado el 28 de julio de 1982.

El problema se tornaba cada vez más grave e imposible de resolver: ya no eran solamente los propietarios de la casa sus destructores; ahora también se les había unido la Institución oficial encargada de salvaguardar nuestro patrimonio: el Instituto Nacional de Antropología e Historia.

Teníamos que darnos por vencidos. Pero en un último intento de, por lo menos, hacer ver que no todos estamos involucrados en el mismo "juego" y como un acto de solidaridad con el pueblo de San Miguel, el 5 de junio publiqué un último artículo en el Excélsior titulado: "La Casa de Correos de San Miguel Allende: ejemplo para prevenir nuevas desgracias".

En él, respondo en parte los absurdos argumentos empleados por el Ing. García Torres, y doy a conocer la Declaratoria en la que se dio el rango de Monumento Nacional, no sólo a la Casa de Correos, sino a toda la ciudad de San Miguel Allende. He aquí su contenido: 
El 17 de abril del presente año apareció en esta misma sección un artículo mío titulado 'La unión hace la fuerza: casa colonial salvada', que se refería a la Casa de Correos de San Miguel de Allende. Pues bien, debo confesar que incurrí en un lamentable error, puesto que al parecer 'ni la unión hace la fuerza', ni hemos salvado nada. No podría precisar las causas de nuestro fracaso, pero en última instancia, ya no importan. El hecho es que los propietarios de esa casa hicieron con ella to que mejor les pareció.

No obstante, yo sigo prefiriendo apegarme a la sabiduría popular, de manera que pondré en práctica otro proverbio que dice que 'no hay peor lucha que la que no se hace' y volveré a insistir en las razones por las cuales esa casa debió ser salvada.

Primera. Esta casa, como todos sabemos y reconocemos, fue construida en el siglo XVIII, lo que de por sí la convierte en un importante testimonio de nuestra historia. Los que no tuvimos la fortuna de nacer en aquella época, por lo menos a través de esa casa podemos darnos cuenta de la manera de vivir de las personas que la habitaron. Además, una casa tan antigua tiene que tener una historia, su propia historia, y entre las funciones que desempeñó esta morada, se encuentra la de haber servido de oficina postal, lo cual le imprime un gran interés en la historia de la población de San Miguel de Allende. Parece simplista, pero, sólo en este punto llevamos dos argumentos capitales por los cuales era necesario rescatar la casa: como testimonio histórico en sí mismo, y como sede de un importantísimo medio de comunicación, asimismo de gran importancia histórica.

Segundo. La casa tiene características formales que no responden al capricho de nadie, sino a las corrientes artísticas del siglo XVIII. Artísticas, no económicas ni comerciales. Por eso, por ejemplo, está distribuida alrededor de un patio. En la fachada luce vanos enmarcados por sencillas molduras formando medios puntos, la cornisa recta y como único ornamento, las guardamalletas debajo del repisón de las ventanas. Como afirmé en un artículo de 13 de marzo del presente año, estas características responden perfectamente a las adoptadas por la arguitectura del Bajío en el siglo XVIII, distintas y originales, a su vez, respecto a las del resto de lo que entonces recibió el nombre de Nueva España. La cornisa recta, por ejemplo, fue muy poco utilizada durante el siglo XVIII. En esa época lo común fueron las cornisas mixtilíneas. Las guardamalletas, en cambio, integran a la casa con las cualidades artísticas predominantes en el resto de la Nueva España. Todo ello hacía de la Casa de Correos de San Miguel un ejemplo único e irrepetible, en cuanto que combinaba hábilmente elementos originales y elementos integradores.

Tercero. La combinación de sus características formales, nos permiten deducir, de acuerdo a la metodología tradicional de la historia del arte, que se trataba de una casa barroca. Para las miradas menos versadas en estos asuntos, la sobriedad de esta casa podría no responder a la riqueza que tradicionalmente se reconoce en el arte barroco. Sin embargo, es barroca, y uno de los elementos de ese estilo que con mayor facilidad puede reconocer el público en ella son, precisamente, las guardamalletas. 
DOI: http://dx.doi.org/10.22201/iie.18703062e.1987.58.1375

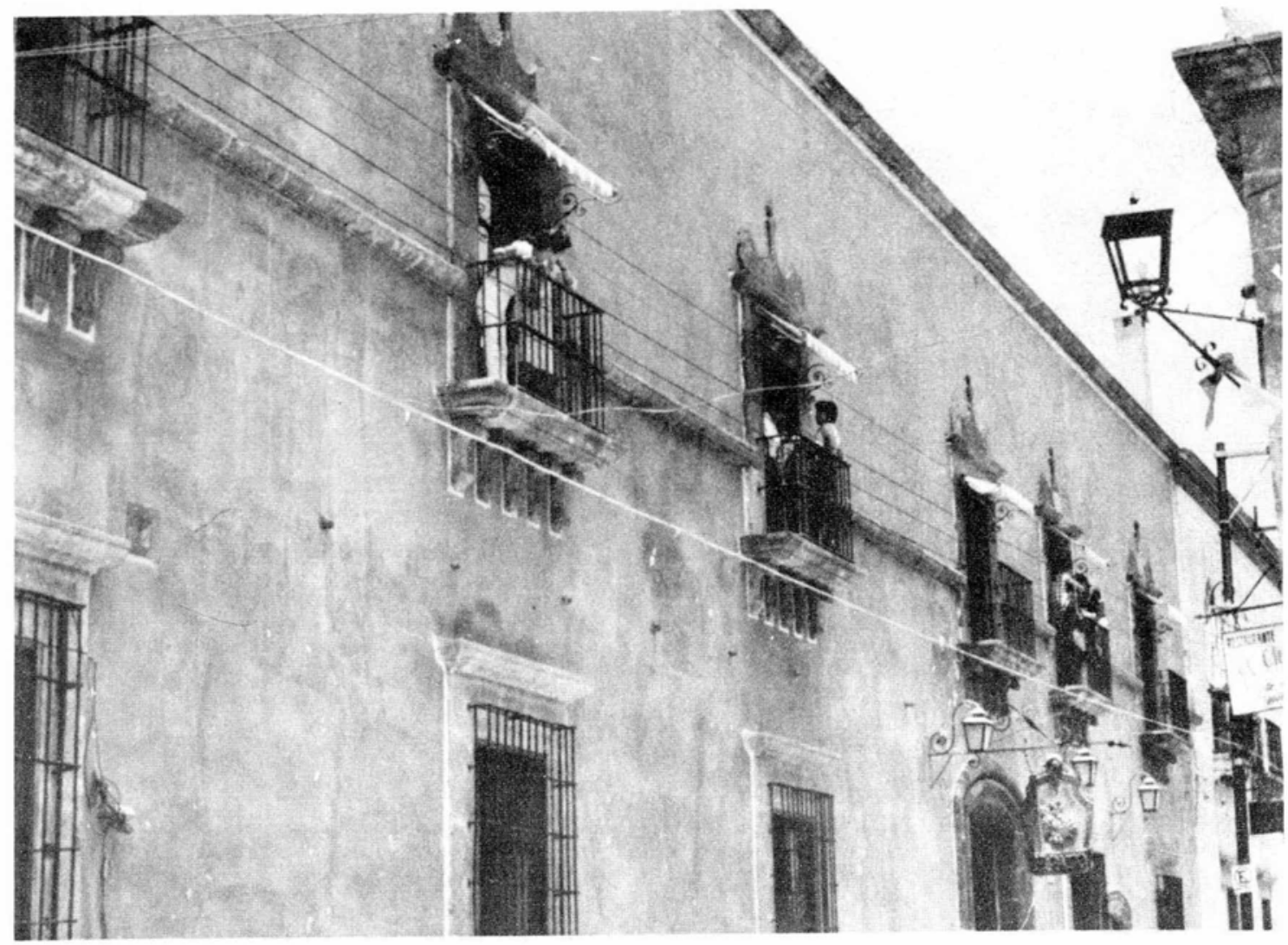

Figura 1. Antigua Casa de Correos en San Miguel Allende, Gto. Con el esplendor de su belleza original. 

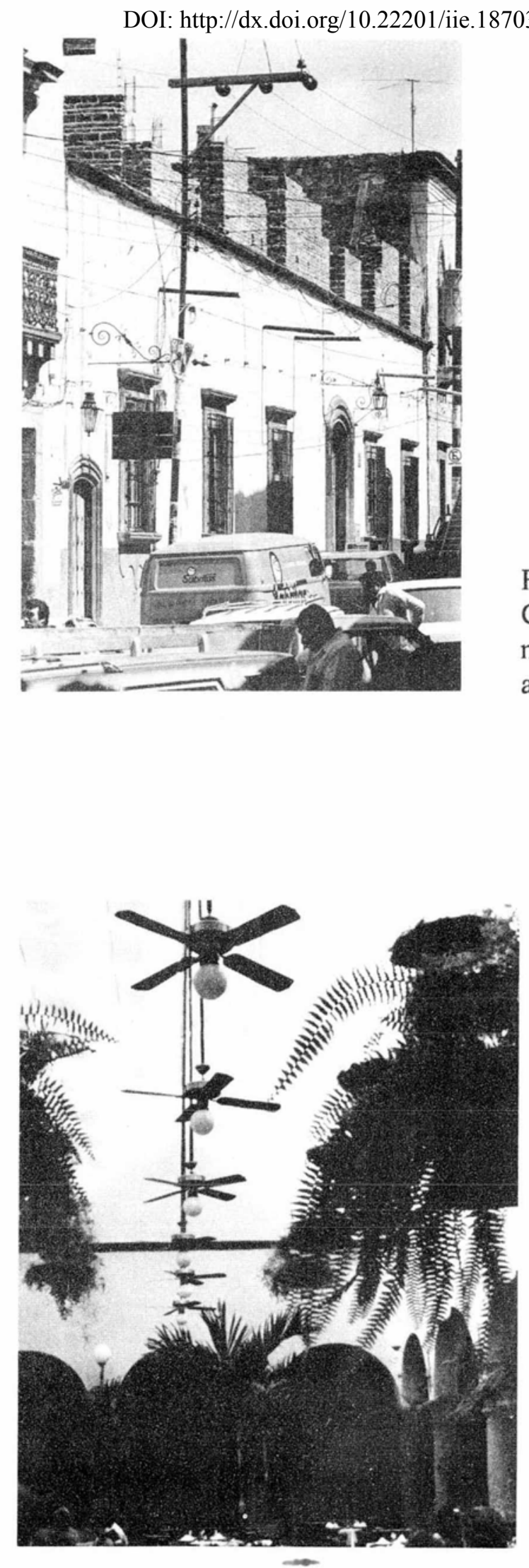

Figura 2. San Miguel de Allende, Gto., antigua Casa de Correos. Agonía del monumento en la época actual.
Figura 3. San Miguel de Allende, Gto., antigua Casa de Correos. ¿Patio colonial o exótico centro nocturno? 
Pero su barroco es especial, tan especial en su sobriedad decorativa, como el alemán, sin que por ello dejemos de reconocer sus cualidades barrocas.

De acuerdo a los puntos segundo y tercero, tenemos suficientes elementos para considerar que la Casa de Correos de San Miguel de Allende debió haberse conservado como estaba. Era un testimonio del arte barroco, no sólo del Baíio, sino de todo México.

Es así como desde el punto de vista histórico y artístico, existían razones de sobra para haberla declarado monumento nacional, y como tal, preservar incólumes sus características originales.

Claro es que la Casa de Correos de San Miguel era la única que se conservaba en esa calle con un solo nivel. Al elevarla a dos niveles, en efecto se igualó el volumen y la proporción de la calle. Pero, por supuesto, no era necesario hacerlo. La calle de Moneda de la ciudad de México perdió "nivel y derecera" al sobresalir una parte del Hospital del Amor de Dios (hoy Academia de San Carlos). Acaso, ¿hemos de tirar el hospital para alinear la calle? Por fortuna ni siquiera nos lo tenemos que cuestionar, porque ese monumento forma parte del patrimonio universitario.

¿A quién afectaba que la Casa de Correos de San Miguel conservara sus características como en el siglo XVIII? A nadie. Al contrario, era un ejemplo único de aquella época de nuestra historia y de aquel estilo artístico que tanto nos enorgullece.

Como dije en el artículo del 17 de abril, parece que no podían tirarse ya las galerías del segundo piso que no daban a la calle, pero, ¿por qué no la que da a la calle? Esa sí que altera totalmente no sólo a la casa, sino finalmente también a la calle, al mostrar la falsedad de los elementos que la integran: las guardamalletas jamás en ninguna parte del mundo fueron utilizadas como remate.

Pero, en fin, los argumentos hasta aquí esgrimidos no forman parte sino del acervo de conocimientos académicos que, por desgracia, no interesan a ciertos sectores sociales, mucho menos a los que sólo tienen en la mirada el signo de dólares. Sin embargo, existe otra razón, que cito al final, pero que debió haber tenido más peso que las anteriores: la voluntad popular. El pueblo de San Miguel Allende no organizó un plantón frente al ayuntamiento par a pedir un hotel, una discoteca, un restaurante o una tienda de artesanías. Ni siquiera para pedir que se abriera un museo. Lo organizó para exigir que no se alterara la Casa de Correos de San Miguel de Allende, para exigir su conservación. El restaurante, el hotel y la discoteca se pudieron haber construido a las afuerzas de San Miguel, con la seguridad de que nadie hubiera protestado, ni siquiera por 'la distancia' que tanto nos preocupa a los capitalinos. Pero resulta bastante desilusionante y poco lógico que la voluntad de una sola persona haya podido estar por encima de la voluntad de todo un pueblo, a menos, claro está, que la casa no hubiera sido declarada nunca monumento nacional, puesto que hasta donde sé, todavía existe la propiedad privada. Sin embargo, contando ya con cualidades históricas y artísticas, y con la voluntad popular, ¿no hubiera sido de todos modos posible declararla 
monumento nacional para preservarla? ¿Es necesario que un inmueble cuente además con otras características para elaborar su declaratoria?

Quizá no, pero ya no interesa. Para sorpresa nuestra, la declaratoria existe. Fue expedida por decreto fechado el 14 de julio de 1982 y publicada en el Diario Oficial de la Federación el 28 de julio del mismo año (tomo CCCLXXIII, número 20). Y es entonces cuando las dudas se multiplican: ¿cómo podemos entender que el INAH haya concedido una licencia para alterar de manera tan flagrante un monumento nacional? ¿Qué papel viene desempeñando el INAH en la custodia del patrimonio nacional?, etcétera, etcétera...

Por ûltimo, para no repetir las preguntas que finalmente todos nos hacemos, sólo agregaré una más: ¿si no el INAH, en este caso, alguien puede tener autoridad estatal o federal suficiente como para respetar la ley? Al menos, ya no por todos los argumentos esgrimidos, sino por uno de los fundamentos del propio decreto: 'Que es indispensable dentro del plan nacional de desarrollo urbano y los planes parciales de desarrollo, la protección, conservación y restauración de las expresiones urbanas arquitectónicas relevantes que constituyen el patrimonio cultural del cual somos depositarios y responsables'.

Es posible que ya no se revuelva nada, pero valga este artículo para hacer del conocimiento de los sanmigueleños que no están solos.

La conclusión que se puede sacar de esta polémica es simple y lamentable: es indudable que efectivamente la voluntad de una persona puede estar por encima de leyes, decretos e intereses comunitarios, siempre que cuente con suficiente poder y dinero para doblegar a las instituciones of $\mathrm{i}^{-}$ ciales y a las autoridades municipales, estatales y federales. 